\title{
Optimum Preparative Method for Storing Cream Puff Paste without Deterioration
}

\author{
Kimio NISHIMURA, ${ }^{1}$ Naoko IMAZUYA ${ }^{1}$ and Shuryo NAKAI ${ }^{2}$ \\ ${ }^{1}$ Department of Food Science and Nutrition, Doshisha Women's College of Liberal Arts, Kamigyo-ku, Kyoto 602, Japan \\ ${ }^{2}$ Department of Food Science, University of British Columbia, Vancouver, B.C., Canada V6T IZ4
}

Received May 19, 1997; Accepted September 8, 1997

\begin{abstract}
When cream puff paste (CPP) was baked after it was kept at $35^{\circ} \mathrm{C}$ for $3 \mathrm{~h}$, it did not puff up as much as one baked just after preparation of the CPP. The optimum preparative method for CPP with the least deterioration during storage was found by carrying out random centroid optimization regarding 9 factors, such as the ratio of flour, shortening, yolk, egg white and water as ingredients, and the heating time at the first stage, the temperature of the heated mixture of water, shortening, and flour on the addition of the egg solution, and the time and temperature of the incubation of the yolk as preparative conditions. The optimum values of $18.0 \%, 14.7 \%, 13.4 \%$, 25.4\%, 28.5\%, $106.5 \mathrm{~s}, 53.9^{\circ} \mathrm{C}, 46.7 \mathrm{~min}$, and $63.7^{\circ} \mathrm{C}$ were obtained, respectively. Each value except the time and temperature for incubating the yolk was similar to that in the standard preparative method of CPP, which brought about deterioration during storage. The incubation of the yolk at $63.7^{\circ} \mathrm{C}$ for $46.7 \mathrm{~min}$ caused a decreased in the specific activity of amylase in the yolk from $1.71 \pm 0.43$ to $0.20 \pm 0.17 \mu$ g of maltose $/ \mathrm{mg}$ of protein but did not affect proteins in the CPP.
\end{abstract}

Keywords: cream puff paste, deterioration, random centroid optimization, amylase, storing cream puff paste

Cream puffs have been extensively used for pastries or dishes made by stuffing with cream or salad. Especially, a cream puff with cream is called "chou cream" and is one of the most popular confections in Japan, though it was invented in France.

Cream puff paste (CPP) is made from flour, egg, and butter or shortening, divided equally into a small mass using an icing syringe and then expanded by baking in the oven so that a cream puff is obtained. The partition of CPP sometimes takes time, so that the CPP is often left. In particular, it is popularly recommended that the mass of CPP should be warm to make a good cream puff (Yoshida, 1980), so the CPP was allowed to stand at about $35^{\circ} \mathrm{C}$ according to circumstances (Ohkita \& Yamada, 1990). Tsuji et al. (1980) found that the ability of expansion of CPP decreased when the CPP was left at room temperature. Ohkita and Yamada (1990) also reported that the same deterioration of CPP occurred upon the preservation of CPP at $35^{\circ} \mathrm{C}$ for $3 \mathrm{~h}$. Imazuya and Kisaki investigated the cause of the deterioration and found that this deterioration also occurred even with CPP made using wheat starch instead of flour (1996a) and that the ability of expansion was inversely proportional to the molecular weight of the starch (1996b). Moreover, the addition of $\mathrm{AgNO}_{3}$ to CPP as an inhibitor of $\alpha$-amylase decreased the deterioration of CPP (Imazuya \& Kisaki, 1996b). These results suggested that lowering the molecular weight of starch by amylase in CPP during storage was responsible for the deterioration of $\mathrm{CPP}$ and that $\mathrm{CPP}$ without substantial deterioration could be obtained by inactivation of amylase. Imazuya and Kisaki also clarified that the activity of amylase in the egg yolk was the strongest of all the ingredients in CPP (1996b). Thus, the preparation of CPP without substantial deterioration could be expected after inactivating the amylase in the yolk.

To obtain such a CPP, in this study, the optimum method was investigated using the random centroid optimization (RCO) (Nakai, 1990; Dou, et al., 1993; Nishimura et al., 1997) for 9 factors, such as the ratio of flour, shortening, yolk, egg white, and water as ingredients, and the heating time at the first stage, the temperature of the heated mixture of water, shortening, and flour on the addition of egg solution, and the time and temperature for the incubating the yolk as preparative conditions. Moreover, the effects of the time and temperature for incubating the yolk, which were new processes, on the proteins in the CPP were also examined.

\section{Materials and Methods}

Materials Soft flour and shortening were purchased from Nisshin Flour Milling Co. (Tokyo) and Asahi Denka Kogyo Co. (Tokyo), respectively. Eggs were purchased in a market. The chemicals used were of guaranteed reagent grade from Nacalai Tesque (Kyoto).

Preparative method for cream puffs Cream puffs were generally prepared according to the following method. Two hundred milliliter of water and $100 \mathrm{~g}$ of shortening were placed in a saucepan $(21 \mathrm{~cm}$ in diameter, $8 \mathrm{~cm}$ in depth) made of heat-resistant glass and heated on a $600 \mathrm{~W}$ hot plate (HS-675G; Hitachi, Ltd., Tokyo). After boiling, $100 \mathrm{~g}$ of soft flour, which was sieved twice though 20 mesh, was added and heated for $90 \mathrm{~s}$ while stirring slowly with a hand mixer (MK-HI; Matsushita Electric Industrial Co., Ltd., Osaka). The heated mixture was then obtained. About 1/6,1/3, 1/3, and $1 / 6$ of the whole weight $(200 \mathrm{~g})$ of egg solution were added to the heated mixture at $0,20,40$, and $60 \mathrm{~s}$ later, respectively, from the time when the heated mixture was cooled to $75^{\circ} \mathrm{C}$. Slow stirring with a hand mixer was 
Table 1. Summary data for random-centroid optimization.

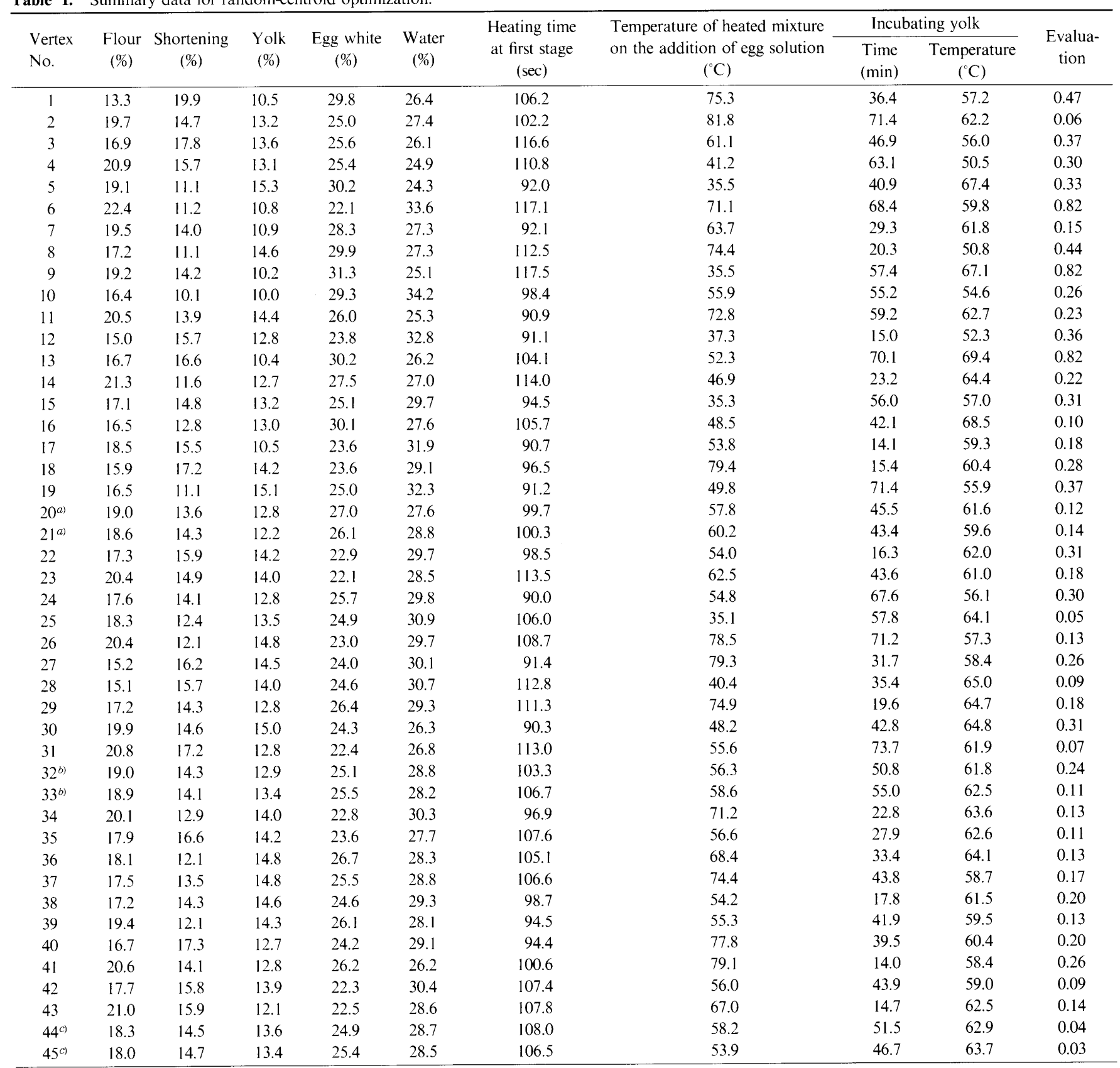

a) Re-centroid points of first cycle.

${ }^{b)}$ Re-centroid points of second cycle.

${ }^{c}$ Re-centroid points of third cycle.

maintained for 2 min after the first addition of egg solution. The CPP was then obtained and called standard CPP. A part of the standard CPP was placed in a plastic film bag (Fukusukekogyo Co., Ltd., Ehime) and kept at $35^{\circ} \mathrm{C}$ for $3 \mathrm{~h}$ in an oven (WFO-450-D; Tokyo Rikakikai Co., Ltd., Tokyo). Ten-grams portions of standard CPP (about $3 \mathrm{~cm}$ in diameter, about $1.5 \mathrm{~cm}$ in height) were made using an icing syringe, then baked at $200^{\circ} \mathrm{C}$ for $20 \mathrm{~min}$ in an oven (RCK10N; Osaka Gas Co., Ltd., Osaka) and left to dry for $10 \mathrm{~min}$ after the oven was turned off. Thus cream puffs were obtained.

Evaluation of cream puffs The cream puffs were evaluated by measuring the ratio of height to diameter, by dividing the height by the mean of the longest and shortest diameters of the baked cream puff, according to the paper by Imazuya and Kisaki (1996b). The value of 0.82 , which was the average obtained from preliminary cream puffs made just after preparation of the standard CPP, was regarded as the best evaluation.

The specific volume of a cream puff, which was calculated by dividing its volume by its weight, was also determined to know the degree of expansion. Because the average specific volume of a cream puff made just after preparation of the standard CPP was about 8.7 , a cream puff having a specific volume under 8.0 was regarded as a poorly expanded cream 

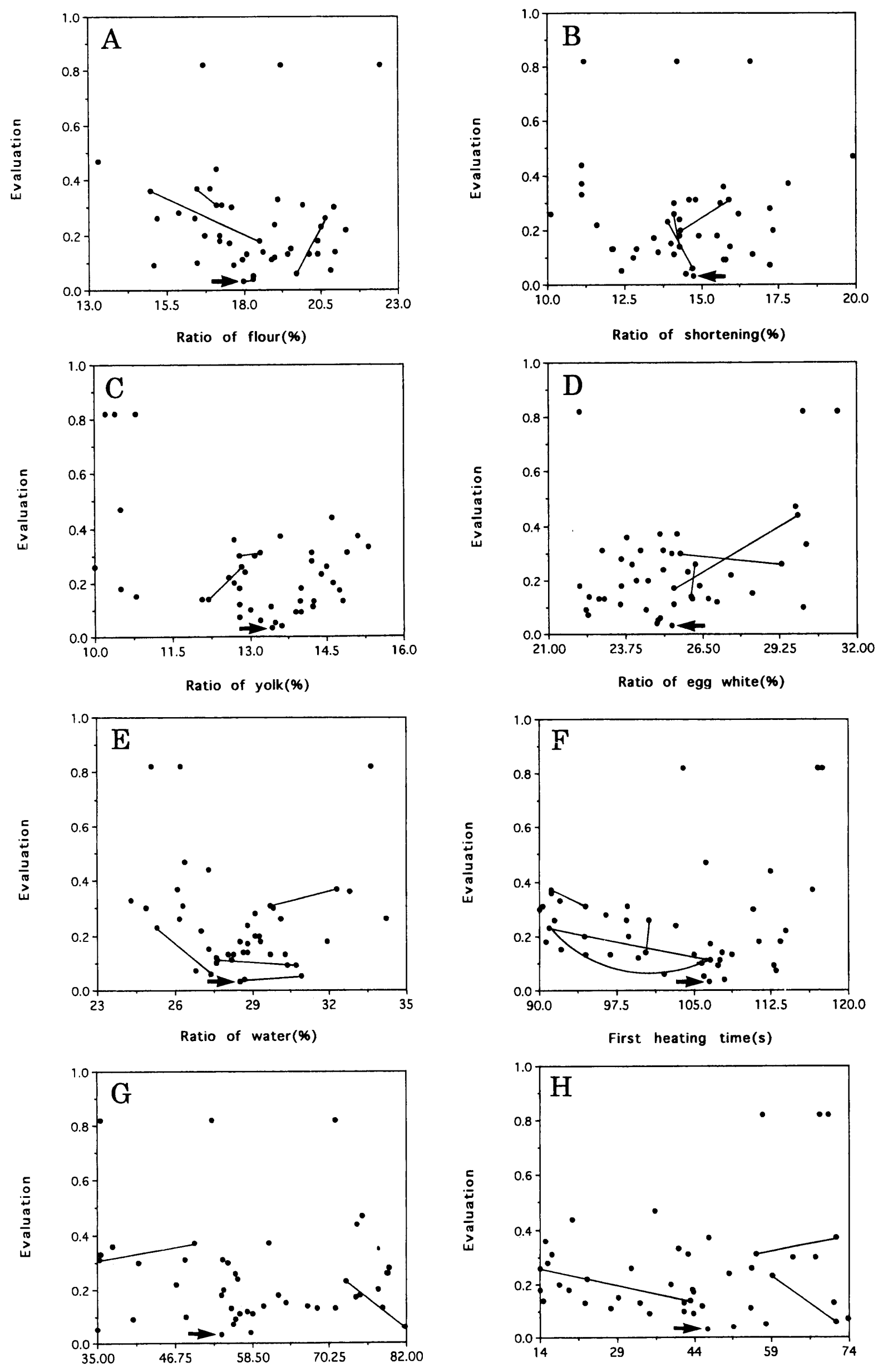

Temperature of heated mixture on addition of egg solution $\left({ }^{\circ} \mathrm{C}\right)$

Time for incubating the yolk(min) 
puff and was given an evaluation value of 0 .

Random centroid optimization ( $R C O$ ) To search for the preparative method for $\mathrm{CPP}$ with the least deterioration during storage, the RCO was used (Nakai, 1990; Dou, et al, 1993; Nishimura et al., 1997). CPPs were prepared according to 45 vertices from the 9 factors of ingredients and preparative conditions. Those CPPs were kept and baked under the same conditions as the standard CPP. The mean of the absolute value obtained by subtracting 0.82 from each ratio of height and diameter in cream puffs made after storage at $35^{\circ} \mathrm{C}$ for 3 $\mathrm{h}$ of each CPP was used for evaluation of the cream puffs, according to the previous paper (Nishimura et al, 1997). The vertex that provided the smallest evaluation was investigated. Triplicates, at least, were independently assessed in the preparation of cream puffs at each vertex. The experimental ranges for each factor were determined with reference to the standard preparative method (Yoshida, 1980) and the conditions for heat-denaturation of yolk proteins (Watanabe, 1980) as follows: flour ratio, 13-23\%; shortening ratio, 10-20\%; yolk ratio, 10-16\%; egg white ratio, 21-32\%; water ratio, 23-35\%; the heating time at the first stage, $90-120 \mathrm{~s}$; the temperature of the heated mixture of water, shortening and flour on the addition of egg solution, $35-82^{\circ} \mathrm{C}$; the time for incubating the yolk, 14-74 min; and the temperature for incubating the yolk, $50-70^{\circ} \mathrm{C}$. CPP without substantial deterioration was obtained and called optimum CPP.

Measurement of amylase activity The activity of amylase in egg was measured by a modification of the method of Noelting and Bernfeld (1948). Yolk solution before and after a $63.7^{\circ} \mathrm{C}$ incubation for $46.7 \mathrm{~min}$ or egg white solution was diluted 40 times with distilled water, and each diluted solution was used as the enzyme solution. A $0.5 \mathrm{ml}$ of $1 \%$ soluble starch in $0.02 \mathrm{M}$ sodium phosphate buffer $(\mathrm{pH} 6.9)$ and $0.5 \mathrm{ml}$ of each enzyme solution were mixed and incubated at $30^{\circ} \mathrm{C}$ for $60 \mathrm{~min}$. The reaction was stopped by boiling the reaction mixture for $90 \mathrm{~s}$ and then adding $1.0 \mathrm{ml}$ of $1 \%$ 3,5-dinitrosalicylic acid and 30\% Rochelle salt in $0.4 \mathrm{~N} \mathrm{NaOH}$ to the reaction mixture. After boiling for $5 \mathrm{~min}$, the reaction mixture was cooled with tap water. After the addition of 10 $\mathrm{ml}$ of distilled water, the mixture was filtered and the optical density at $500 \mathrm{~nm}$ of the diluted filtrate was measured using a spectrophotometer (UV-140; Shimadzu, Kyoto). The amount of maltose generated by amylase was then calculated. The protein in each enzyme solution was measured by the method of Lowry et al. (1951). The specific activity was obtained by dividing the amount of maltose by the amount of protein and $60 \mathrm{~min}$.

Micro-observation of starch granules in standard and optimum CPP The changes in starch granules in both CPPs during storage at $35^{\circ} \mathrm{C}$ for $3 \mathrm{~h}$ were observed using a microscope (PM-10AD; Olympus Optical Co., Ltd., Tokyo), after the starch granules were stained with $0.013 \%$ iodine solution containing $0.003 \%$ potassium iodide.

Measurement of reducing sugar in CPP The changes in the amount of reducing sugar in standard and optimum CPPs during storage were measured by the method of Somogyi (1952). Ninety seven and one-half milliliters of water was added to each $2.5 \mathrm{~g}$ of both CPPs before and after storage at $35^{\circ} \mathrm{C}$ for $3 \mathrm{~h}$, and the mixture was homogenized. After centrifugation at $5000 \times g$ for $10 \mathrm{~min}$ at $4^{\circ} \mathrm{C}$, the supernatant was filtered to remove oil. One milliliter of copper reagent, which consisted of $2.5 \%$ sodium carbonate, $2.5 \%$ potassium sodium ( + )-tartrate, $2 \%$ sodium hydrogen carbonate, $20 \%$ sodium sulfate, and $0.6 \%$ copper (II) sulfate, was added to $1 \mathrm{ml}$ of filtrate and boiled for $10 \mathrm{~min}$. After this mixture was cooled rapidly, $1 \mathrm{ml}$ of Nelson reagent, which was composed of $1.6 \%$ hexaammonium heptamolybdate and $0.19 \% d i$-sodium hydrogen arsenate in $0.11 \mathrm{~N}_{2} \mathrm{SO}_{4}$, was added and left for $10 \mathrm{~min}$. Twenty-two milliliters of distilled water was then mixed and left for $15 \mathrm{~min}$. The optical density at $660 \mathrm{~nm}$ was measured using a spectrophotometer (UV-140; Shimadzu, Kyoto). The amount of reducing sugar was calculated as glucose.

Unless otherwise stated, at least triplicates were indepen-

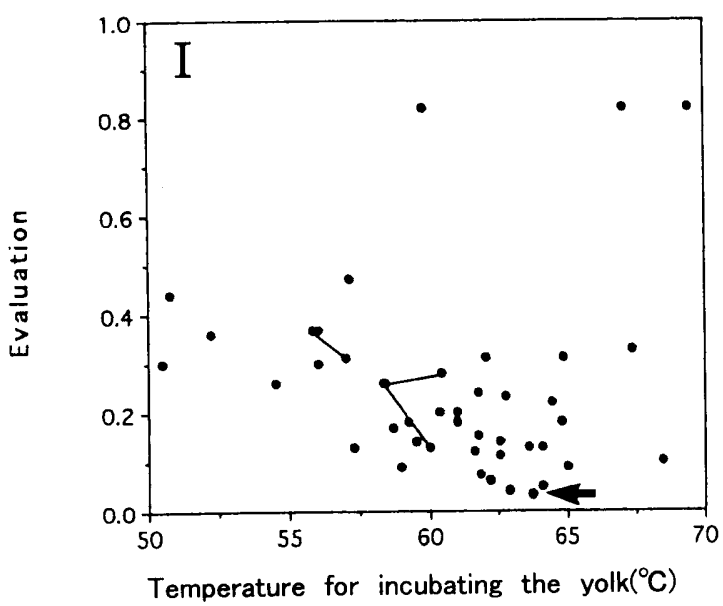

Fig. 1. Mapping results of the third cycle of experiments generated by random centroid optimization. (A) the ratio of flour, (B) the ratio of shortening, (C) the ratio of yolk, (D) the ratio of egg white, (E) the ratio of water, $(F)$ the heating time at the first stage, $(G)$ the temperature of the heated mixture of water, shortening and flour on the addition of egg solution, $(\mathrm{H})$ the time for incubating the yolk, (I) the temperature for incubating the yolk. Lines indicate probable trends. ( $)$ was each vertex. Evaluation: The mean of the absolute value obtained by subtracting 0.82 from each ratio of height and diameter in the cream puffs made after storage at $35^{\circ} \mathrm{C}$ for $3 \mathrm{~h}$ of each CPP was used for evaluation of the cream puffs. 
dently assessed in each experiment, and the average \pm standard deviation was calculated except for the experiment for determining the optimum CPP. Statistical differences were evaluated using the Student's $t$-test.

\section{Results and Discussion}

Search for a preparative method for optimum CPP by the $R C O$ To obtain the optimum CPP, the ratio of flour, shortening, yolk, egg white, water, the heating time at the first stage, the temperature of the heated mixture of water, shortening, and flour on the addition of egg solution, and the time and temperature for incubating the yolk were optimized using the RCO (Table 1). Values for the parameters in each experiment were given by the RCO program and then used in each preparation of cream puffs. All data were mapped (Fig. 1, A-I). The mapping process aids in visualization of the experimental response surface, indicating the trend of the data (Nakai et al., 1984). RCO is usually repeated until one gets a response considered adequate. After the third cycle of the RCO program, in this study, the approximate position of the optimum was clear. The best result was obtained at the vertex 45 with flour, 18.0\%; shortening, 14.7\%; yolk, 13.4\%; egg white, 25.4\%; water, $28.5 \%$; the heating time at the first stage, $106.5 \mathrm{~s}$; the temperature of the heated mixture on the addition of egg solution, $53.9^{\circ} \mathrm{C}$; the time for incubating the yolk, $46.7 \mathrm{~min}$; and the temperature for incubating the yolk, $63.7^{\circ} \mathrm{C}$. The comparison of these values and those used in making standard CPP is shown in Table 2, and the photographs of cream puffs made using both conditions are shown in Fig. 2. Cream puffs made by baking the standard and optimum CPPs just after preparation (Fig. 2, A and C) had a value of $0.82 \pm 0.07(n=5)$ and $0.89 \pm 0.06(n=12)$ as the ratio of the height and diameter, respectively. The ratio of the cream puffs made by baking the standard CPP preserved for $3 \mathrm{~h}$ at $35^{\circ} \mathrm{C}$ was lowered to $0.66 \pm 0.05(n=5)$ (Fig. 2B). On the other hand, one of cream puffs made using the optimum CPP after keeping it at $35^{\circ} \mathrm{C}$ for $3 \mathrm{~h}$ was $0.85 \pm 0.05(n=8)$ (Fig. 2D), and the difference between both ratios before and after storage of the optimum CPP was much smaller than those of cream puffs baked using the standard CPP. There are no great differences between the ratios of each ingredient (from flour to water in Table 2) in the standard and optimum preparation conditions. This must be because the parameters that have been used until now were optimized based on experience. The

Table 2. Comparison with standard and optimum conditions.

\begin{tabular}{lcc}
\hline \multirow{2}{*}{ Factors } & \multicolumn{2}{c}{ Conditions } \\
\cline { 2 - 3 } & Standard & Optimum \\
\hline Ratio of flour (\%) & 16.7 & 18.0 \\
Ratio of shortening (\%) & 16.7 & 14.7 \\
Ratio of yolk (\%) & & 13.4 \\
Ratio of egg white (\%) & 33.3 & 25.4 \\
Ratio of whole egg (\%) & 33.3 & 28.5 \\
Ratio of water (\%) & 90.0 & 106.5 \\
Heating time at first stage (s) & 75.0 & 53.9 \\
Temperature of heated mixture & & \\
$\quad$ on the addition of egg solution $\left({ }^{\circ} \mathrm{C}\right)$ & & 46.7 \\
Time for incubating the yolk (min) & & 63.7 \\
Temperature for incubating the yolk $\left({ }^{\circ} \mathrm{C}\right)$ & & \\
\hline
\end{tabular}

biggest differences are in the time and temperature for incubating the yolk among the 9 factors, because the standard condition did not include these two procedures. It could be thought that those procedures caused the suppression of deterioration of CPP during storage at $35^{\circ} \mathrm{C}$ for $3 \mathrm{~h}$. Thus, the effects of both procedures were investigated.

Imazuya and Kisaki already indicated that the deterioration of CPP during storage depended on the lowering of the molecular weight of starch by amylase in the yolk (1996b). These preparative conditions were newly set up for the inactivation of this amylase. Next, we investigated whether the activation of amylase was decreased by the incubation of the yolk.

Effects of incubation of yolk on the activity of amylase The activities of amylase in native and incubated yolk at $63.7^{\circ} \mathrm{C}$ for $46.7 \mathrm{~min}$ and in native egg white were measured (Table 3). The specific activity of amylase in the native yolk was about $1.7 \mu \mathrm{g}$ of maltose $/ \mathrm{mg}$ of protein, but this activity was almost lost during the incubation at $63.7^{\circ} \mathrm{C}$ for $46.7 \mathrm{~min}$. The activity in native egg white was hardly detected, indicating that the incubation of the yolk at $63.7^{\circ} \mathrm{C}$ for $46.7 \mathrm{~min}$ was responsible for the inactivation of amylase in $\mathrm{CPP}$, and the deterioration of CPP during storage at $35^{\circ} \mathrm{C}$ for $3 \mathrm{~h}$ was then depressed. Next, the effects of incubating the yolk on starch granules in both CPPs were examined with a

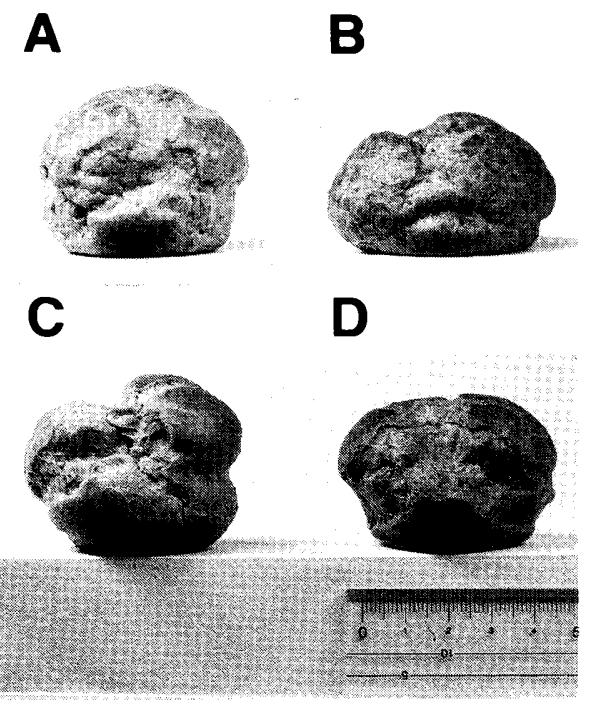

Fig. 2. Effects of storage on cream puffs made by baking standard or optimum CPP. (A) and (B) were cream puffs obtained using the standard CPP and the stored standard mix, respectively. (C) and (D) were obtained using the cream puffs made of optimum CPP and the stored optimum mix, respectively.

Table 3. Effects of incubation of yolk on activity of amylase.

\begin{tabular}{lcc}
\hline \multirow{2}{*}{ Incubation at $63.7^{\circ} \mathrm{C}$ for $46.7 \mathrm{~min}$} & \multicolumn{2}{c}{$\begin{array}{c}\text { Specific activity of amylase } \\
(\mu \mathrm{g} \text { of maltose } / \mathrm{mg} \text { of protein })\end{array}$} \\
\cline { 2 - 3 } & \multicolumn{1}{c}{ Yolk } & Egg white \\
\hline Not done & $1.71 \pm 0.43$ & $0.33 \pm 0.15$ \\
Done & $0.20 \pm 0.17^{* *}$ & \\
\hline
\end{tabular}

Each value is the mean $\pm \operatorname{SD}(n=3)$. The value with ${ }^{* *}$ is significantly different from the control at $p<0.01$ in the same column. 
A

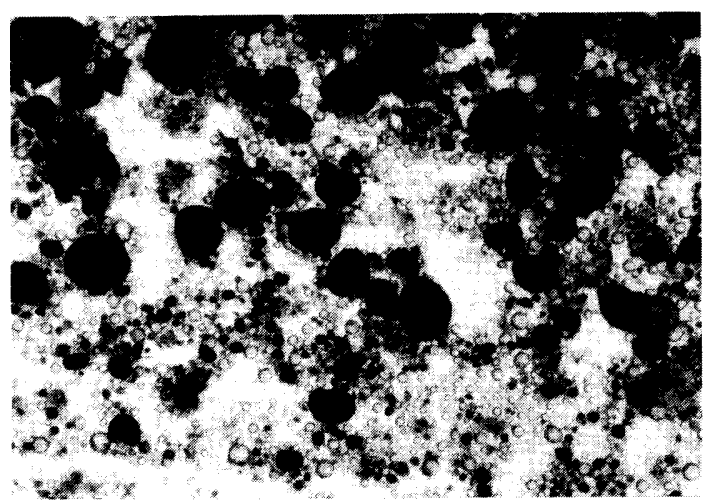

$\mathrm{C}$

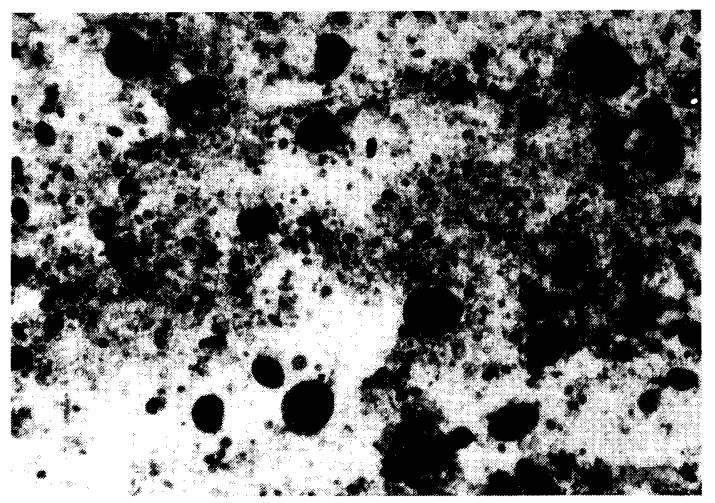

B

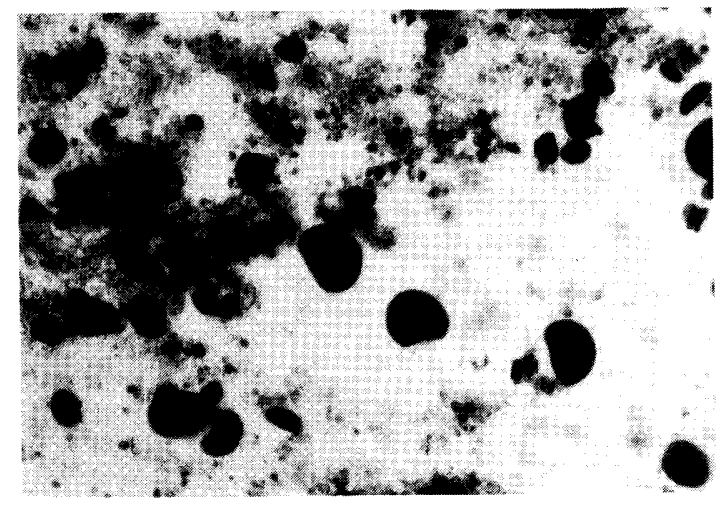

$\mathrm{D}$

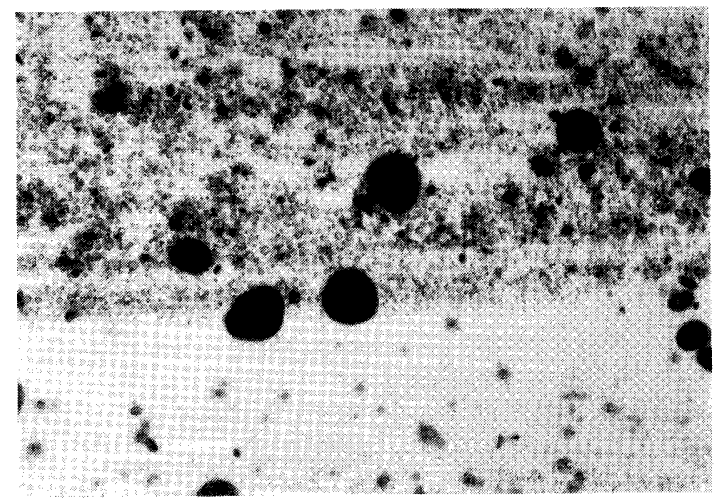

$100 \mu \mathrm{m}$

Fig. 3. Changes in starch granules in both CPPs during storage $(\times 150)$. Standard CPP (A) was kept at $35^{\circ} \mathrm{C}$ for $3 \mathrm{~h}$ so that the stored standard mix $(\mathrm{B})$ was obtained. Optimum CPP (C) was kept under the same conditions and the stored optimum mix (D) was also obtained. The starch granules in each sample were stained with $0.013 \%$ iodine solution including $0.003 \%$ potassium iodide.

microscope.

The changes in starch granules in standard and optimum CPPs during storage at $35^{\circ} \mathrm{C}$ for $3 \mathrm{~h}$ The changes in starch granules in both CPPs during storage were observed with a microscope (Fig. 3). The starch granules were stained with $0.013 \%$ iodine solution containing $0.003 \%$ potassium iodide. The shapes of the starch granules in standard CPP before storage were uniform and round (Fig. 3A), but those after storage had become distorted (Fig. 3B). On the other hand, the shapes of almost all the starch granules in optimum CPP before storage were also round, though there were a few crescent-shaped starch granules (Fig. 3C), and a great influence of storage on the shape of the starch granules was not observed in optimum CPP (Fig. 3D). This observation indicated that the starch granules in standard CPP were damaged by amylase, but that the those in optimum CPP were not destroyed by amylase, because of its loss of activity.

Changes in the amounts of glucose in both CPPS during storage The amounts of reducing sugar in both CPPs before and after storage were measured by the method of Somogyi (1952) as glucose (Table 4). The amounts of glucose in both the standard and optimum CPPs were about $200 \mathrm{mg}$, and there was no significant difference between these
Table 4. Changes in amounts of glucose in CPP during storage.

\begin{tabular}{lcc}
\hline \multirow{2}{*}{ Preparation conditions of CPP } & \multicolumn{2}{c}{$\begin{array}{c}\text { Amounts of glucose } \\
\text { (mg of glucose/100 g of CPP) }\end{array}$} \\
\cline { 2 - 3 } & before storage & after $3 \mathrm{~h}$ of storage \\
\hline Standard conditions & $192.3 \pm 7.48$ & $587.6 \pm 134.40$ \\
Optimum conditions & $204.6 \pm 6.50$ & $259.4 \pm 28.47^{*}$ \\
\hline
\end{tabular}

Each value is the mean $\pm \mathrm{SD}(n=3)$. The value with ${ }^{*}$ is significantly different from the control at $p<0.05$ in the same column.

values. However, that in the standard CPP increased to about $590 \mathrm{mg}$ after storage. On the other hand, the amounts of glucose in optimum CPP hardly increased, suggesting that the inactivation of amylase by incubating the yolk inhibited the decrease in the molecular weight of starch, so that deterioration was depressed. From the results described above, it seemed that the new procedure, incubation of the yolk, depressed any effects brought about by amylase.

When starch is heated, gelatinization occurs. This gelatinized starch supports the network of gluten in bread and improves the loaf volume. Though our sample was a cream puff, it could be thought that starch had a similar role. Accordingly, the cause of the decrease in puffing development when using CPP stored for hours might be responsible for the 
non-formation of support by starch due to the lowering of molecular weight of starch by amylase. Actually, our optimum preparative conditions for CPP inhibited the decrease in the molecular weight of starch by amylase so that good cream puffs could be made after hours of storage.

Moreover, the effects of this incubation procedure for the yolk newly used in the preparation of optimum CPP on the proteins in CPP were investigated using sodium dodecyl sulfate-polyacrylamide gel electrophoresis analysis. It was found that this new procedure did not affect the proteins in CPP (data not shown).

Accordingly, in this study, it was clarified that the incubation of the yolk at $63.7^{\circ} \mathrm{C}$ for $46.7 \mathrm{~min}$ suppressed the deterioration of CPP during storage by depressing the activity of amylase but did not affect the proteins in CPP.

Acknowledgments The authors are grateful to Ms. Hiroko Ueda, Yasuyo Kobayashi, Yuki Tsujinaka, Yasuko Maeda, Kyoko Takenaka, Asako Tanaka, Kazuyo Tamamura, and Yukari Nakazawa for their assistance.

\section{References}

Dou, J., Toma, S. and Nakai, S. (1993). Random-centroid optimization for food formulation. Food Res. Int., 26, 27-37.

Imazuya, N. and Kisaki, H. (1996a). Deterioration of the expansion of chou crust baked from preserved chou paste. Nihon Chourikagakukaishi, 29(2), 87-92 (in Japanese).

Imazuya, N. and Kisaki, H. (1996b). Influences of $\alpha$-amylase on the expansion of chou crust. Nihon Chourikagakukaishi, 29(2), 93-97 (in Japanese).

Lowry, O.H., Rosebrough, N.J., Farr, A.L. and Randall, R.J. (1951). Protein measurement with the folin phenol reagent. J. Biol. Chem., 193, 265-275.

Nakai, S., Koide, K. and Eugster, K. (1984). A new mapping supersimplex optimization for food product and process development. $J$. Food Sci, 49, 1143-1148, 1170

Nakai, S. (1990). Computer-aided optimization with potential application in biorheology. J. Jpn. Soc. Biorheol, 4(4), 143-152.

Nishimura, K., Goto, M., Imazuya, M. and Nakai, S. (1997) Optimum cooking conditions for Indica type rice by using random centroid optimization. Nihon Chourikagakukaishi, 30, 9-16 (in Japanese).

Noelting, G. and Bernfeld, P. (1948). Sur les enzymes amylolytiqucs III. La $\beta$-amylase: dosage d'activité et contrôle de l'absence d' $\alpha$-amylase. Helv. Chim. Acta., 31, 286-290.

Ohkita, S. and Yamada, M. (1990). The relation between preserving temperatures or periods of cream puff paste and hollow development. Nihon Chourikagakukaishi, 23(1), 73-80 (in Japanese).

Somogyi, M. (1952). Notes on sugar determination. J. Biol. Chem., 195, 19-23.

Tsuji, M., Tani, Y., Katayama, Y. and Kurosawa, S. (1980). Effects on the qualities of cream puff by management of the paste. Doshisha Kasei, 14, 31-39 (in Japanese).

Watanabe, K. (1980). Coagulation and gelation. In "Science and Utilization of Egg," ed. by Y. Sato. Chikyu-sha, Tokyo, pp. 205-217 (in Japanese).

Yoshida, K. (1980). "The Technique of Pastry," Shibata-shoten, Tokyo (in Japanese). 